\title{
EDITORIAL: REGIONAL COMMUNITIES
}

\author{
Yukiko UCHIDA ${ }^{1)}$ and Kosuke TAKEMURA ${ }^{2)}$ \\ ${ }^{1)}$ Kokoro Research Center, Kyoto University, Japan \\ ${ }^{2)}$ Faculty of Economics, Shiga University, Japan
}

Psychology basically focuses on psychological and behavioral mechanisms at an individual level, but it also needs to explore macro level and collective phenomena. Especially in social psychology and cultural psychology, researchers have investigated group process, organizational behavior, and the mechanisms of cultural/institutional effects on psychological functions. Among them, studies on regions and local communities have become more important than before. For example, after the severe damage from the Great East Japan earthquake, people in Japan found out the power of social networks in regional communities. However, we have not fully elucidated what constitutes the important component of "region," which is a rather obscure concept. Sometimes we can say it is a platform of community. We can also define it as geographical neighborhood that shares certain ecological contexts. To provide the current insight of regional studies more clearly, this special issue of Psychologia includes a collection of papers that conduct regional studies from a multidisciplinary approach, including psychology, anthropology, and action research.

Regions, neighborhoods, and communities are difficult to define precisely, but we can say that they are the place where we construct and maintain cultural resources, obtain local knowledge and folk theory, and culturally shared ideas (Bruner, 1990) as well as our own personal and social identities. It is also where we cooperate and collaborate with each other. Several studies from a wide range of disciplines have revealed that characteristics of macro level society (e.g., region, neighborhood, and community) have unique influences on psychological and behavioral mechanisms, which cannot be reduced to the effects of individual level traits. This includes psychological research on happiness (Han, Kim, Lee, \& Lee, 2013), sociological research on violent crime (Sampson, Raudenbush, \& Earls, 1997), and anthropological studies on prosocial behavior (Holland, Silva, \& Mace, 2012). These studies suggest that human psychology and behavior are inseparable from surrounding social contexts, including contexts that they collectively create in regional communities.

Cultural psychologists have emphasized a very similar view. "Culture and psych make each other up" (Shweder, 1991) is one of the important theoretical and working hypotheses cultural psychologists use to try to identify the mechanism of this mutual

Correspondence concerning this article should be addressed to Yukiko Uchida, Kokoro Research Center, Kyoto University, 46 Yoshida Shimoadachicho, Sakyo-ku, Kyoto 606-8501, Japan (e-mail: uchida.yukiko.6m@ kyoto-u.ac.jp). 
constitution. Empirical studies so far have tried to investigate this issue from cross-national comparison studies, such as EAST vs. WEST, and have found that several psychological mechanisms are actually different between them (see Markus \& Kitayama, 1991; Nisbett, Peng, Choi, \& Norenzayan, 2001, for reviews).

From such effort, many researchers including scholars outside of cultural psychology have come to notice the importance of "culture," which is a macro level concept by nature, when we understand psychological functions. Yet, the unit of "culture" is still unclear. Sometimes we indiscriminatingly adopt nation as a unit of culture, but we should think about the unit of culture that leads to certain psychological tendencies and provides shared reality. "Region" can also be a unit, which provides cultural practices as well as shared realities and meaning systems.

Recently, cultural psychological studies have started to move on to next steps from focusing only on cross-national study, to including regional differences within nations, which can elucidate the effect of local network and socio-environmental factors on psychological functions. For example, Uskul, Kitayama, and Nisbett (2008) found that in Turkey, members of farming and fishing communities exhibited greater holistic cognition (a tendency to attend to the broad perceptual and cognitive field) than members of herding communities. Similarly, Talhelm et al. (2014) found that in China, rice-growing areas are more holistic and interdependent than wheat-growing areas. Kitayama, Ishii, Imada, Takemura, and Ramaswamy (2006) also found regional differences within Japan, suggesting that residents of Hokkaido, which is Japan's northern island and has a history of voluntary settlement, showed greater tendencies toward independence than other areas in Japan (see also Yamagishi, Hashimoto, Li, \& Schug, 2012, for a different opinion).

These studies on regional differences have two implications. First, nation is not necessarily a unit of culture. Regions within nations can have their own culture, and people have different psychological tendencies across regions. People live in multi-layered cultural contexts. For example, living in Japan and speaking the Japanese language might have the power to create "nation-culture" related psychological tendencies, while living in Kyoto (Japan's ancient capital), speaking Kyoto dialect, and following Kyoto-specific local rules might also have the power to create "region-culture" related psychological tendencies. Thus, in order to clarify the mutual construction system between culture and psyche, we have to take multi-layered culture into consideration. Second, investigation of regional differences helps to elucidate what causes cultural differences in psychological functions. Though cross-national comparisons have succeeded in showing that psychological functions vary largely across societies, researchers have struggled to identify specific factors creating such differences. Several factors, such as language, formal education systems, and legal systems, co-vary across nations. By investigating regional differences within a nation in which people share such factors, possible factors creating cultural differences in psychological functions can be narrowed down. Uskul et al. (2008), for example, suggested that holistic cognition, which is more prevalent in East Asia than in North America, is likely to be promoted by social interdependence through the comparison of communities differing in the level of social interdependence but locating in the same country. 
Culture is created and maintained (and sometimes changed) through social interactions. Studies on social interactions and relationships in regional societies, where people collectively create their own culture, have the potential to untangle complex processes of mutual constitution between psyche and culture.

Not only from such scientific needs, but also from the position of applied science, regional studies also provide initial implications to consider sustainable well-being, especially in Japan, where people have experienced radical population decrease in local areas. To support a sustainable future, we need to know how we build and maintain social capital, collective well-being, and regional identity in local areas and neighborhoods. Therefore, we strongly believe that studies investigating dynamics of regional communities should be well acknowledged as researchers construct interdisciplinary research fields. From this special issue, we attempt to make progress in social science on regional studies.

The first paper by Hitokoto, Takahashi, and Kaewpijit reports a study of happiness among adults living in rural and urban areas in Thailand. Though the number of crosscultural studies involving Asian societies has dramatically increased, the majority of data comes from specific countries of East Asia (e.g., China, Korea, and Japan). Hitokoto et al.'s study contributes to the literature of happiness and culture by examining the generalizability of a newly developed scale for interdependent conception of happiness in the context of another country in Asia. They also provide findings about socio-economic factors that influence the meaning of happiness, which deepen our understanding about important components of cultural notions shared by residents.

Takemura, Uchida, and Fujino contribute to studies of social capital in fishing communities in Japan. Their research focused on the process of how professional social coordinators (extension officers) build and maintain trust in communities and how they improve the quality of life of community members. They found out that the activities and coordination roles by professionals (extension officers) promote social capital and welfare in local communities. The authors also compared fishing and farming communities and provided an important implication on the difference across socio-ecological situations. The paper suggested that farming and fishing areas have their own unique style of shared reality, local rules, and psychological functions, even though they have similarities to each other.

Zi's paper reports anthropological research conducted in Botswana, Southern Africa. She investigated reasons why Chinese goods, which are famous among local people for low quality, have widely spread in the country. Through participant observation and interviews with local residents, she revealed that the government, mass media, Chinese merchants, and local residents have their own incentives that created complex contexts in which Chinese goods successfully prevailed. This research illustrates the importance of listening to a variety of voices to fully understand complex social contexts.

In the last paper, Kusago and Miyamoto raised an important implication on regional studies from the idea of action research, which should be derived not only from an academic approach but also from experiences, opinions, and needs of local people. Then, the authors developed the process evaluation method as a tool for community-based action research. The article describes how this approach can be applied to community life improvement and 
well-being in local communities by presenting the case study of the Kizawa community in Niigata, Japan. This new strategy does not only treat region as a target of the research, but also as a collaborating partner.

Through the editorial process, we noticed that these regional studies exhibit potential for leadership in social science. We really hope you enjoy reading the publications in this issue.

\section{REFERENCES}

Bruner, J. S. 1990. Acts of meaning. Cambridge, MA: Harvard University Press.

Han, S., Kim, H., Lee, E.-S., \& Lee, H.-S. 2013. The contextual and compositional associations of social capital and subjective happiness: A multilevel analysis from Seoul, South Korea. Journal of Happiness Studies, 14, 1183-1200.

Holland, J., Silva, A. S., \& Mace, R. 2012. Lost letter measure of variation in altruistic behaviour in 20 neighbourhoods. PLoS ONE, 7, e43294.

Kitayama, S., Ishii, K., Imada, T., Takemura, K., \& Ramaswamy, J. 2006. Voluntary settlement and the spirit of independence: Evidence from Japan's "Northern frontier". Journal of Personality and Social Psychology, 91, 369-384.

Markus, H. R., \& Kitayama, S. 1991. Culture and the self: Implications for cognition, emotion, and motivation. Psychological Review, 98, 224-253.

Nisbett, R. E., Peng, K., Choi, I., \& Norenzayan, A. 2001. Culture and systems of thought: Holistic versus analytic cognition. Psychological Review, 108, 291-310.

Sampson, R. J., Raudenbush, S. W., \& Earls, F. 1997. Neighborhoods and violent crime: A multilevel study of collective efficacy. Science, 277, 918-924.

Shweder, R. A. 1991. Cultural psychology: What is it? In R. A. Shweder (Ed.), Thinking through cultures: Expeditions in cultural psychology (pp. 73-110). Cambridge, MA: Harvard University Press.

Talhelm, T., Zhang, X., Oishi, S., Shimin, C., Duan, D., Lan, X., et al. 2014. Large-scale psychological differences within China explained by rice versus wheat agriculture. Science, 344, 603-608.

Uskul, A. K., Kitayama, S., \& Nisbett, R. E. 2008. Ecocultural basis of cognition: Farmers and fishermen are more holistic than herders. Proceedings of the National Academy of Sciences of the United States of America, 105, 8552-8556.

Yamagishi, T., Hashimoto, H., Li, Y., \& Schug, J. 2012. Stadtluft Macht Frei (City Air Brings Freedom). Journal of Cross-Cultural Psychology, 43, 38-45. 